\title{
Post-brushing rinsing for the control of dental caries: exploration of the available evidence to establish what advice we should give our patients
}

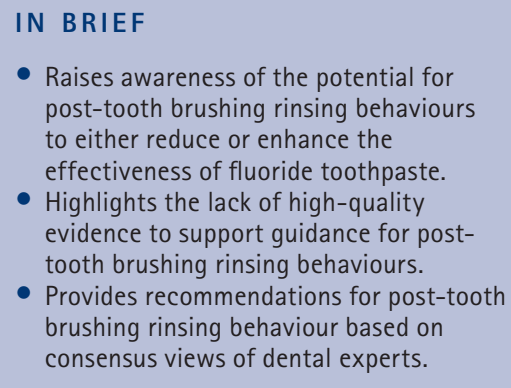

\author{
N. Pitts, ${ }^{1}$ R. M. Duckworth, ${ }^{2}$ P. Marsh, ${ }^{3}$ B. Mutti, ${ }_{1}^{4}$ C. Parnell ${ }^{5}$ and D. Zero ${ }^{6}$
}

Post-tooth brushing rinsing behaviours have the potential to either reduce or enhance the effectiveness of fluoride toothpaste and show wide variation in the general population. There is a lack of high-quality evidence to support definitive guidance in this area. However, the currently available international guidelines provide consistent recommendations despite the limited evidence. To explore the available evidence base and recommendations on optimal post-brushing rinsing behaviour relating to the use of both water and mouth rinses, a meeting was held between the authors and other experts. This paper reports the consensus views of those present at the meeting concerning what advice we should give our patients. A full list of meeting attendees is provided at the end of this article.

\section{INTRODUCTION}

Oral care products for home-use play an important part in the prevention and control of oral diseases such as caries and periodontal disease. Fluoride toothpaste is the most widely used topical fluoride modality for caries prevention and control worldwide. There is a body of high-quality evidence regarding the optimal concentration of fluoride in toothpaste for caries prevention, the frequency of brushing and, to a lesser extent, the amount of toothpaste to be used (particularly in young children). Rinsing with water or a mouth rinse after tooth brushing is also a common practice. Ideally oral hygiene procedures should complement each other, yet the method of rinsing and the product used for rinsing (for example, water, fluoride

\footnotetext{
${ }^{1 *}$ Director of the Centre for Clinical Innovations and Professor of Dental Health, University of Dundee, Dundee; ${ }^{2}$ Honourary Lecturer, Newcastle University, Newcastle upon Tyne; ${ }^{3}$ Professor of Oral Microbiology, University of Leeds, UK; ${ }^{4}$ Associate Director RED Product Development, Johnson \& Johnson, Germany; ${ }^{5}$ Researcher, Oral Health Services Research Unit, University College, Cork, Ireland; ${ }^{6}$ Director of the Oral Health Research Institute, Professor and Chair Department of Preventive and Community Dentistry, Associate Dean for Research, Indiana University School of Dentistry, Indianapolis, IN, USA

${ }^{*}$ Correspondence to: Professor Nigel Pitts

Email:n.b.pitts@dundee.ac.uk
}

\section{Refereed Paper}

Accepted 1 March 2012

DOI: $10.1038 /$ sj.bdj.2012.260

${ }^{\circledR}$ British Dental Journal 2012; 212: 315-320 mouth rinse or antimicrobial mouth rinse) could potentially either reduce or enhance the effectiveness of fluoride toothpaste. Despite this important interaction, this is an area in which there is little guidance for the patient or the dental practitioner. The consensus recommendations described in this paper are based on an exploration of the different types of evidence currently available and the knowledge gaps that exist. Although the range and quality of evidence on optimal post-brushing rinsing behaviour relating to the use of both water and mouth rinses is variable, recommendations from professional organisations on post-brushing rinsing appear to be consistent.

The goal of oral health maintenance is to prevent and control caries and other oral diseases through a multifaceted approach, which for dental caries takes into account tooth resistance, biofilm, diet and rate of disease progression.

Plaque biofilms develop in a structured way over time. The developing biofilm synthesises extracellular polymers that form a functional matrix, which can modify the movement of molecules within the biofilm. Mature plaque is more difficult to remove than a newly formed biofilm and may contain more pathogenic bacteria. ${ }^{1}$

Strategies to control caries include effective oral hygiene practices to reduce biofilm development, reduction in sugar consumption and frequency to restrict periods of acidic challenge to teeth, as well as a range of interventions to increase tooth resistance. Furthermore, oral disease can be prevented not only by directly inhibiting the putative pathogens, but also by interfering with the environmental factors driving the selection and enrichment of these bacteria. Several traits of cariogenic bacteria make good targets for components of mouth rinses that aim to control plaque or tooth demineralisation. These targets include: inhibition of sugar transport, inhibition of rapid production of acid, interference with the acid tolerance of the bacteria and blocking synthesis of intracellular and extracellular polysaccharides. Clearly any agent in a mouth rinse must be active against the selected target; capable of penetrating and then being retained within the biofilm; must not adversely affect oral microbial ecology and must not generate resistance or select for exogenous pathogens. ${ }^{1}$

Antiplaque agents can reduce biofilm formation by altering the properties of the surface at risk of colonisation and/or removing established biofilm. Antimicrobial agents may kill target organisms, but they can also be effective if they slow bacterial growth and/or inhibit cariogenic traits. For example, effective agents may slow plaque growth/regrowth or they may prevent development of a 
damaging $\mathrm{pH}$ within the biofilm, thereby reducing the acidic challenge to the tooth and eliminating the acidic environment that selects for cariogenic bacteria. Mouth rinses are effective vehicles for delivering antimicrobial or antiplaque agents, although the pharmacokinetics and mode of action of any active ingredient must be consistent with this delivery route.

Historically, the anticaries benefits of fluoride have been proven for toothpastes, mouth rinses, gels and drinking water, etc. Fluoride works in a range of ways including acidification of the bacterial cell interior, which disrupts enzyme systems and inhibits growth of the organism. ${ }^{2}$

A group of experts gathered to examine and document the available evidence and the gaps in this field through a series of presentations given by the authors. The experts then formulated consensus statements relating to rinsing behaviour and the prevention of dental caries. The evidence for these statements and the consensus statements themselves are provided in this publication.

\section{SALIVARY FLUORIDE CLEARANCE AND MOUTH RINSES}

Oral hygiene procedures should ideally complement one another. Mouth rinses are well accepted and widely used in combination with brushing and flossing. Many ingredients in mouth rinses have been evaluated for their plaque-reducing effectiveness and their ability to eliminate mutans streptococci. Apart from fluoride, such ingredients include chlorhexidine, essential oils, triclosan, cetylpyridinium chloride, sanguinarine, sodium dodecyl sulphate and metal ions (tin, zinc, copper). Mouth rinses containing fluoride have the largest body of scientific evidence supporting their anticaries efficacy and health benefits and this knowledge is discussed here. Evidence from a pilot study also suggests that a fluoride rinse may even be a more effective way of delivering topical fluoride than fluoride dentifrice, based on fluoride retention in saliva. ${ }^{3}$

Fluoride is bound in plaque biofilms and is released when the bacteria start to make acid and the $\mathrm{pH}$ within the biofilm falls. Fluoride has two modes of antimicrobial action. It prevents enrichment of organisms such as Streptococcus mutans by inhibiting critical metabolic processes (direct effect). In addition, by reducing environmental acidification in biofilms, fluoride removes the conditions that give $S$. mutans a competitive advantage (indirect effect). ${ }^{4}$

Salivary fluoride clearance is a common surrogate used to assess the potential anticaries efficacy of fluoridated oral care treatments. A typical mean salivary fluoride clearance curve is formed by plotting salivary fluoride clearance on a logarithmic scale against time. The resultant curve is typically biphasic, with an initial rapid drop in fluoride concentration over the first 30 min followed by a slow decline. The initial fall reflects salivary wash-out of unbound fluoride. During the latter phase, it is believed that fluoride is released from an oral fluoride reservoir. Labile fluoride, stored in oral fluoride reservoirs at the time of topical treatment application, may maintain a prolonged protective effect against dental caries. ${ }^{5}$

Use of a fluoride mouth rinse affects oral retention of fluoride. ${ }^{6}$ Duckworth and colleagues demonstrated that the inclusion of 100 ppm fluoride in a mouth rinse compensated for the loss of oral fluoride after an oral hygiene regimen that combined brushing with fluoridated toothpaste followed by rinsing with a non-fluoridated mouth rinse. ${ }^{6}$ This study further showed that rinsing with a fluoridated mouth rinse could contribute more effectively to inhibition of caries if used between brushings. The authors concluded that rinsing with a $100 \mathrm{ppm}$ fluoride mouth rinse soon after brushing with a standard fluoride toothpaste should not interfere with the toothpaste's anticaries protection. However, rinsing with a non-fluoride mouth rinse soon after brushing with standard fluoride toothpaste may reduce the anticaries protection provided by brushing with a fluoride toothpaste alone. ${ }^{6}$

To maintain the anticaries benefit of a standard fluoride toothpaste, a mouth rinse should therefore contain at least 100 ppm fluoride if it is to be used at any time, including soon after brushing. A nonfluoride mouth rinse should preferably be applied at different times of the day to a standard fluoride toothpaste so as to avoid the 'wash-out phenomenon' that impacts on the benefit of the fluoride toothpaste.

If oral fluoride levels increase with increasing applied fluoride dose for both mouth rinses and dentifrices, a further question concerns whether this dependence is related to applied fluoride concentration or applied fluoride amount. A study by Duckworth and colleagues demonstrated that fluoride concentration in mouth rinses appears to be a more important factor than applied fluoride volume in determining the elevation of oral fluoride levels following topical fluoride use. ${ }^{7}$ Therefore, application of a fluoride dose in a smaller volume and at a higher concentration than the current norm, may increase efficacy without increasing adverse effects. ${ }^{7}$

Rinsing habits also play an important role in the oral retention of fluoride from dentifrices and may, in turn, affect their clinical efficacy. ${ }^{8}$ Approximal sites benefit significantly more from fluoridated rinses than the more exposed buccal sites in children and adults, but this is affected by the rinsing technique used. ${ }^{9,10}$

\section{THE ROLE OF FLUORIDE IN MOUTH RINSES}

Several systematic reviews have evaluated the effectiveness and safety of fluoride mouth rinses in the prevention of dental caries. A review by Marinho and colleagues $^{11}$ of 34 studies involving 14,600 children and adolescents concluded that the regular and supervised use of fluoride mouth rinse by children is associated with a clear reduction in caries increment. Studies in older children have shown similar outcomes, although the benefit is less marked in children who already use a fluoridated dentifrice daily. Twetman and colleagues $^{12}$ found that fluoride mouth rinses may have a caries-protective effect in children with limited exposure to other sources of fluoride, but any additional effect is questionable in children who already use a fluoridated dentifrice daily. Consequently, when considering both efficacy and cost-effectiveness, it has been recommended that fluoride mouth rinsing is targeted at individuals at high risk of caries. ${ }^{12-15}$

A variety of fluoride compounds are used in mouth-rinse formulations including sodium fluoride (NaF), stannous fluoride $\left(\mathrm{SnF}_{2}\right)$, sodium monofluorophosphate $\left(\mathrm{Na}_{2} \mathrm{FPO}_{3}\right)$ and amine fluoride. These are available at a range of concentrations, for example, 0.2\% NaF (909 ppm F), 0.05\% 
$\mathrm{NaF}$ (226 ppm F), and 0.02\% NaF (100 ppm F). Products may be acidulated or neutral. Other ingredients include surfactants, humectants, flavouring, sweetener, colouring and preservatives.

Many fluoride mouth rinses contain other agents, such as essential oils. A two week in situ trial (a large study for investigations of this type, but still providing a lower level of evidence than from in vivo randomised controlled trials) evaluated the remineralising effect of an essential oil fluoride mouth rinse versus a non-essential oil fluoride mouth rinse (the positive control) or an essential oil non-fluoride mouth rinse (the negative control). This concluded that an essential oil mouth rinse with $100 \mathrm{ppm}$ fluoride is effective at promoting enamel remineralisation and fluoride uptake. ${ }^{16}$ Furthermore, the combination of fluoride and essential oils in a mouth rinse may provide anticaries efficacy in addition to the previously established antigingivitis efficacy of essential oils. Overall, the essential oil mouth rinse with $100 \mathrm{ppm}$ fluoride used in a twice-daily $20 \mathrm{ml}, 30 \mathrm{~s}$ rinsing regimen demonstrated effects comparable with those of the $\mathrm{NaF}$ mouth rinse regimens currently approved for caries protection by the US food and drug administration. ${ }^{17}$

There are many factors that influence the effectiveness of mouth rinses and these are summarised in Table 1.

Studies show that for mouth rinses, higher fluoride concentrations are more effective than lower concentrations in enhancing remineralisation of white spot lesions, although there is some debate about the lowest concentration with anti-caries efficacy. ${ }^{18,19}$

\section{REVIEW OF FLUORIDE PRODUCT USE AND ASSOCIATED SCIENTIFIC SUPPORT}

Tooth brushing habits among the general population are far from optimal. For example, a survey of children's toothbrushing habits in 41 countries ${ }^{20}$ found variations in the proportion of boys brushing more than once a day: 52\% in Ireland; 63-67\% in England, Wales and Scotland and 39\% in Finland.

The effectiveness of fluoride toothpaste depends on many factors, but the two that can most easily be controlled are the fluoride toothpaste formulation and user behaviour. With respect to user behaviour, a systematic review by Marinho and colleagues ${ }^{21}$ found that frequency of use was important. There was a $14 \%$ reduction in caries increment when moving from once- to twice-daily brushing.

A wide variation is also observed in post-brushing rinsing behaviours in clinical and real-life settings. ${ }^{8,9,22}$ The four most common methods of post-brushing rinsing appear to be using a beaker, sipping directly from the tap, sipping from cupped hands and using a toothbrush to convey water to the mouth. There also appear to be cultural differences in rinsing habits. ${ }^{23}$ Overall, rinsing after tooth brushing appears to be the norm, with rinsing with water being most popular.

A specific search conducted in PubMed, combining terms for tooth brushing and rinsing, found four studies that reported the caries increment to be higher in people who reported rinsing with large volumes of water after brushing compared with those who used little or no water. . $224-26^{2}$

The difference in caries increment across these studies ranged from $6 \%{ }^{24}$ to $16 \%$. Three studies reported the difference in effect was statistically significant - the more thorough the rinse, the greater the caries increment.

Chesters and colleagues ${ }^{22}$ concluded that rinsing methods may have a direct effect on caries increment and to gain optimum benefit from toothpaste, rinsing with an excessive volume of water should be avoided. Ashley and colleagues ${ }^{25}$ similarly concluded that the preferred practice was to rinse with a small volume of water after brushing. ${ }^{25}$

A modified tooth brushing technique with fluoride toothpaste rinsing has shown further benefits in both children and adults in terms of reductions in caries increment. ${ }^{9,10}$ The technique involves spreading the toothpaste evenly on the teeth and then brushing for two minutes and not expectorating more than necessary during brushing. A sip of water may be taken $(10 \mathrm{ml})$ to create a slurry of toothpaste that is actively swished around the dentition by active cheek movements for one minute before expectorating. There should be no further water rinsing, and no eating or drinking for two hours after brushing.
Table 1 Factors that influence the effectiveness of fluoride mouth rinses

\section{Factor}

Fluoride concentration ${ }^{3,32-34}$

Fluoride compound $-\mathrm{NaF}_{1} \mathrm{Na}_{2} \mathrm{FPO}_{3^{\prime}} \mathrm{SnF}_{2^{\prime}}$ amine $\mathrm{F}^{35-36}$

Mouth rinse $\mathrm{pH}^{37}$

Rinsing volume $e^{7,38}$

Rinsing time ${ }^{16,38}$

Rinsing frequency - once daily, twice daily, weekly, or every two weeks ${ }^{39-40}$

Timing of fluoride mouth rinse use: $: 71-43$

Before or after meals

Morning versus bedtime

After fluoride dentifrice use

Oral physiology: 3,17,41,44

Salivary flow rate

Oral architecture

Prior dental plaque removal ${ }^{45}$

Post-fluoride mouth rinsing behaviour:

Eating and drinking

Talking

A Cochrane systematic review ${ }^{27}$ of the effect of combinations of topical fluorides versus a single topical fluoride included five clinical trials that compared the cariespreventive effect of the combined use of fluoride toothpaste and fluoride mouth rinse with that of fluoride toothpaste and placebo rinse. Although the pooled result favoured the combined regimen, the difference was not statistically significant (prevented fraction 0.07, 95\%; CI 0.00 $0.13, \mathrm{p}=0.06$ ).

Fluoridated rinses have shown benefits for caries reduction over non-fluoridated rinses. Petersson and colleagues ${ }^{28}$ compared the clinical effect on primary root caries of daily use of a toothpaste and mouth rinse with fluoride (amine fluoride and potassium fluoride $250 \mathrm{ppm}$ F) versus a placebo mouth rinse in an adult population at risk of caries. The results showed significantly more reversals of root caries with the fluoride mouth rinse than the placebo.

\section{CLINICAL GUIDELINES}

Currently, there is a lack of recommendations regarding optimal use of mouth rinses after tooth brushing. The experts identified several relevant guidelines from different countries, some of which have considered post-brushing rinsing behaviour. Differences were found in the 
recommendations and in the evidence level or grade given to the same recommendation (due to variations in the way guidelines are developed in different countries). However, there appears to be agreement across a number of evidencebased guidance documents on general recommendations for post-brushing rinsing behaviour, even if the methods used to grade the evidence and the evidence levels vary (Table 2).

The consistent message emerging from the guidelines in Table 2 is to spit and avoid excessive rinsing with water. The main supporting evidence for these recommendations comes from four clinical studies discussed earlier. ${ }^{22,24-26}$

Specific recommendations regarding the use of fluoride rinses include:

- Department of Health and British

Association for the Study of

Community Dentistry: ${ }^{29}$ daily rinse

with $0.05 \% \mathrm{NaF}$ at a different time to brushing

- Australian Research Centre for Population Oral Health: ${ }^{30}$ use the rinse at a different time to toothpaste

- New Zealand Guidelines Group: ${ }^{31}$ after rinsing, mouth rinse should be spat out not swallowed. This guideline differs from the others as the expert advisory group developing the guideline decided that 'if people are using mouth rinse, then there is no harm in using it at the same time as brushing'.

In conclusion, post-brushing rinsing is the norm, with some evidence that the rinsing method, especially the volume of water, may impact on the caries-preventive effect of fluoride toothpaste. Guideline recommendations are consistent on post-brushing rinsing (spit, avoid rinsing with water/ excessive rinsing with water), however, the evidence base is limited. Recommendations that a fluoride mouth rinse be used for individuals at high risk of caries and at a different time to tooth brushing are generally consistent, but once again the evidence base is limited.

\section{CONSENSUS REVIEW AND CONCLUSIONS}

Whilst there was not complete consensus on comprehensive clinical recommendations, given the variable range and levels of evidence on optimal post-brushing rinsing

Table 2 Common recommendations across guidelines to spit and avoid rinsing/ excessive rinsing with water

\begin{tabular}{|c|c|c|c|c|}
\hline Guideline (year) & Target population & Level of evidence & Country & Grade of recommendation \\
\hline SIGN $47(2000)^{46}$ & $\begin{array}{l}\text { High caries risk } \\
\text { aged } 6-16 \text { years }\end{array}$ & $16^{\circ}$ & Scotland & $A^{*}$ \\
\hline SIGN $83(2005)^{47}$ & Pre-school children & $1++$ and 1-" & Scotland & $A^{*}$ \\
\hline IOHSGI (2009) $)^{48}$ & $\begin{array}{l}\text { Children aged } \\
0-15 \text { years }\end{array}$ & $1+$ and $3^{+}$ & Ireland & $\mathrm{B}^{+}$ \\
\hline $\operatorname{EAPD}(2009)^{49}$ & Children & 'Insufficient' & Europe & Not given \\
\hline $\begin{array}{l}\text { DoH and BASCD } \\
(2009)^{29}\end{array}$ & Children and adults & $\mathrm{IV}^{\dagger}$ & UK & None used \\
\hline $\operatorname{SDCEP}(2010)^{50}$ & $\begin{array}{l}\text { Children aged } \\
0-16 \text { years }\end{array}$ & None given & Scotland & None used \\
\hline $\operatorname{AAPD}(2009)^{51}$ & Children & None used & USA & None used \\
\hline $\begin{array}{l}\text { ARCPOH (2006) } \\
\text { (Australia) }^{30}\end{array}$ & All ages & None used & Australia & None used \\
\hline
\end{tabular}

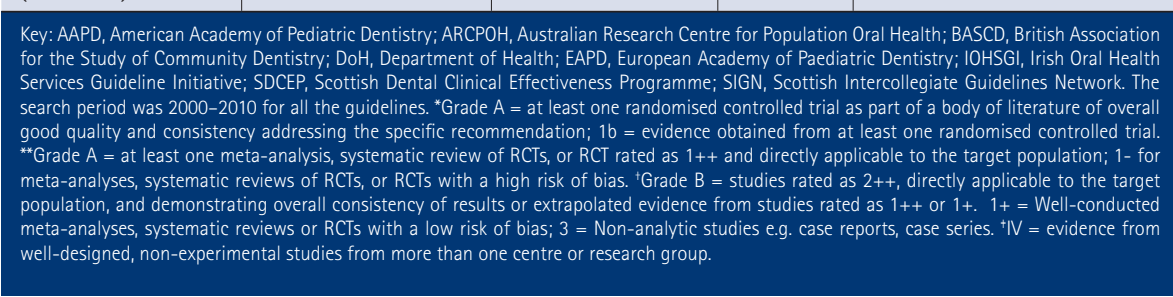

Table 3 Consensus statements on post-brushing rinsing behaviour

Consensus statements

Rinsing with water after brushing with fluoride toothpaste can reduce the benefit of fluoride toothpaste.

There is a theoretical benefit in keeping the intra-oral levels of fluoride elevated by replacing a post-brushing water rinse with a fluoride rinse.

Non-fluoride rinses should preferably be used before brushing or at a different time to brushing with fluoride toothpaste.

Mouth rinses containing fluoride can be used after brushing with fluoride toothpaste.

The panel endorsed the promotion of the positive messages from the research by Sjögren et al.9.47 concerning use of a slurry of fluoride toothpaste.

All three documented methods of increasing post-brushing fluoride retention - (a) 'spit don't rinse', (b) rinsing with a slurry of fluoride toothpaste and saliva and (c) rinsing with a mouth rinse containing fluoride - could be beneficial for caries control at the individual level.

There is a need to tackle the risk profile for dental caries in populations. To this aim, the panel supported Sir Michael Marmot's strategy of 'proportionate universalism.52 This approach advocates improving the oral health of all by flattening the social gradient of disease, with a focus on seeking the greatest improvement in those with highest need while still achieving improvements in other population groups.

On the basis of balancing risks and benefits, the panel recommended:

For children at high risk of caries:

- Rinsing should be supervised until an age where parents/carers are confident that children will not drink the rinse

- Mouth rinses should not be used before the age of 6 years. (However, studies in Japan have indicated that 4-5-year-olds can rinse under supervision. In addition, children with newly erupting teeth may gain a longterm benefit from using mouth rinses) ${ }^{53}$

- Use $10 \mathrm{ml}$ twice daily of mouth rinse up to $100 \mathrm{ppm}$ fluoride, or $10 \mathrm{ml}$ once daily of mouth rinse up to $226 \mathrm{ppm}$ fluoride

- Avoid the risk of approaching the lethal dose of fluoride by using an appropriate bottle size.

For the general population, including children aged 12 years and above:

- Brush twice daily with a fluoride toothpaste; do not rinse excessively with water; use one of the three recognised post-brushing approaches to enhance fluoride retention.

The panel also encouraged future research with a range of mouth rinse products to explore the effects of the interplay between the frequency of use of mouth rinse agents and fluoride concentration.

behaviour relating to the use of both water and mouth rinses, the meeting participants developed consensus statements, which are summarised in Table 3. Because of the lack of the highest quality evidence in this area, the participants noted that these statements constitute expert opinion and should be recognised as such. 
There are many gaps in the evidence available for review and research should be prioritised in these areas. For instance, there is a paucity of information on postbrushing rinsing habits of children and adults in different cultures. In addition, little is known about the comparative efficacy of brush/avoid rinsing versus brush/ use fluoride mouth rinse strategies. More data are also required on the optimal concentration of the fluoride mouth rinse and timing of its use. Further research needs to be conducted on the mouth's 'fluoride reservoir' and the effect of fluoride products on this reservoir over a period of weeks. The assembled group also felt that it is now accepted that there is a need for biofilm 'control' rather than eradication, that is, the aim is reduction/disturbance of the biofilm rather than elimination of all biofilm/plaque. There is still a requirement to brush technically well to ensure plaque removal and ensure that the biofilm quality remains benign. There is also a need for greater understanding of what the dental profession thinks and says and does in this area.

\section{MEETING ATTENDEES}

- Chair: Professor Nigel Pitts, Director of the Centre for Clinical Innovations and Professor of Dental Health, University of Dundee, Dundee

- Dr Nigel Carter, Chief Executive, British Dental Health Foundation, Rugby, Warwickshire

- Professor Gail Douglas, Department of Dental Public Health, Leeds Dental Institute, Leeds

- Dr Ralph M. Duckworth, Honourary Lecturer, Centre for Oral Health Research, Newcastle University, Newcastle upon Tyne

- Professor Carlos González-Cabezas, Associate Professor, School of Dentistry, University of Michigan, Ann Arbor, USA

- Dr Roberto Labella, Associate Director of Scientific and Professional Affairs, Johnson \& Johnson

- Professor Peter Lingström, Department of Cariology, Institute of Odontology, University of Gothenburg, Gothenburg, Sweden

- Professor Phil Marsh, University of Leeds, Leeds

- Dr Bruna Mutti, Associate Director
R\&D Product Development, Johnson \& Johnson, Germany

- Professor Denis O’Mullane, Emeritus Professor and Consultant in the Oral Health Services Research Centre, Cork University Dental School and Hospital, Wilton, Ireland

- Dr Carmel Parnell, Oral Health Services Research Unit, University College Cork, Cork, Ireland

- Professor Dr Cor van Loveren, Academic Centre for Dentistry Amsterdam, Amsterdam, The Netherlands

- Professor William Wade, Head of Infection Research Group, King's College London Dental Institute, London

- Professor Helen Whelton, Director, Oral Health Services Research Unit, Department of Oral Health and Development, University College Cork, National University of Ireland, Cork, Ireland

- Professor Domenick Zero, Indiana University School of Dentistry, Indianapolis, IN, USA

\section{DECLARATION OF INTERESTS}

All the participants received remuneration from Johnson \&t Johnson for their participation at the meeting, leading to the development of this publication.

Professor Zero has received research funding from many oral care companies including, most recently, GlaxoSmithKline and Johnson \& Johnson. He has also received compensation in the past from Proctor \& Gamble, Colgate Palmolive and Unilever for consulting activities.

Professor Pitts has received researchrelated funding from a number of oral care companies.

Dr R. M. Duckworth is an independent research consultant who conducts work for a number of oral care companies.

Dr P.D. Marsh has no interests to declare.

Editorial support was provided by Dr Sabah Al-Lawati, Anthemis Consulting Ltd and was funded by Johnson \& Johnson Ltd. The assistance of Ian Mason in making a comprehensive record of the all-day meeting is also gratefully acknowledged.

1. Marsh P D. Microbiology of dental plaque biofilms and their role in oral health and caries. Dent Clin North Am 2010; 54: 441-454.

2. Marquis R E, Clock S A, Mota-Meira M. Fluoride and organic weak acids as modulators of microbial physiology. FEMS Microbiol Rev 2003; 26: 493-510.

3. Zero D T, Fu J, Espeland M A, Featherstone J D. Comparison of fluoride concentrations in unstimulated whole saliva following the use of a fluoride dentifrice and a fluoride rinse. J Dent Res 1988; 67: 1257-1262.

4. Bradshaw D J, Marsh P D, Hodgson R J, Visser J M. Effects of glucose and fluoride on competition and metabolism within in vitro dental bacterial communities and biofilms. Caries Res 2002; 36: $81-86$.

5. Duckworth R M, Morgan S N. Oral fluoride retention after use of fluoride dentifrices. Caries Res 1991. 25: 123-129.

6. Duckworth R M, Maguire A, Omid N, Steen I N, McCracken G I, Zohoori FV. Effect of rinsing with mouthwashes after brushing with a fluoridated toothpaste on salivary fluoride concentration. Caries Res 2009; 43: 391-396.

7. Duckworth R M, Stewart D. Effect of mouthwashes of variable $\mathrm{NaF}$ concentration but constant $\mathrm{NaF}$ content on oral fluoride retention. Caries Res 1994; 28: 43-47.

8. Duckworth R M, Knoop D T, Stephen K W. Effect of mouthrinsing after toothbrushing with a fluoride dentifrice on human salivary fluoride levels. Caries Res 1991: 25: 287-291.

9. Sjögren K, Birkhed D, Ruben J, Arends J. Effect of post-brushing water rinsing on caries-like lesions at approximal and buccal sites. Caries Res 1995: 29: 337-342.

10. Sonbul H, Birkhed D. The preventive effect of a modified fluoride toothpaste technique on approximal caries in adults with high caries prevalence. A 2-year clinical trial. Swed Dent $J$ 2010; 34: 9-16.

11. Marinho V C, Higgins J P, Logan S, Shieham A. Fluoride mouthrinses for preventing dental caries in children and adolescents. Cochrane Database Syst Rev 2003; (3): CD002284.

12. Twetman $S$, Petersson L, Axelsson S et al. Cariespreventive effect of sodium fluoride mouthrinses: a systematic review of controlled clinical trials. Acta Odontol Scand 2004; 62: 223-230.

13. Stamm J W, Bohannan H M, Graves R C, Disney J A. The efficiency of caries prevention with weekly fluoride mouthrinses. J Dent Educ 1984; 48: 617-626.

14. Disney J A, Bohannan H M, Klein S P, Bell R M. A case study in contesting the conventional wisdom: school-based fluoride mouthrinse programs in the USA. Community Dent Oral Epidemiol 1990; 18: 46-56.

15. Centers for Disease Control and Prevention. Recommendations for using fluoride to prevent and control dental caries in the United States. MMWR Recomm Rep 2001; 50: 1-42.

16. Zero D T, Zhang J Z, Harper D S et al. The remineralizing effect of an essential oil fluoride mouthrinse in an intraoral caries test. J Am Dent Assoc 2004: 135: 231-237.

17. Department of Health and Human Services, Food and Drug Administration. Anticaries drug products for over-the-counter human use: final monograph. Federal Register 1995; 60: 52474. Online article available at http://www.fda.gov/ downloads/Drugs/DevelopmentApprovalProcess/ DevelopmentResources/Over-the-CounterOTCDrugs/ StatusofOTCRulemakings/ucm080389.pdf (accessed July 2011).

18. Alexander S A, Ripa L W. Effects of self-applied topical fluoride preparations in orthodontic patients. Angle Orthod 2000; 70: 424-430.

19. O'Reilly M M, Featherstone J D. Demineralization and remineralization around orthodontic appliances: an in vivo study. Am J Orthod Dentofacial Orthop 1987; 92: 33-40.

20. Currie C, Gabhainn S N, Godeau E et al. Inequalities in young people's health: HBSC international report from the 2005/2006 survey. Copenhagen: WHO Regional Office for Europe, 2008.

21. Marinho V C, Higgins J P, Sheiham A, Logan S. Fluoride toothpastes for preventing dental caries in children and adolescents. Cochrane Database Syst Rev 2003; (1): CD002278.

22. Chesters R K, Huntington E, Burchell C K. Stephen $K W$. Effect of oral care habits on caries in adolescents. Caries Res 1992; 26: 299-304. 
23. van Loveren $C$, Ketley C E, Cochran J A, Duckworth $\mathrm{R} M, \mathrm{O}$ 'Mullane D M. Fluoride ingestion from toothpaste: fluoride recovered from the toothbrush, the expectorate and the after-brush rinses. Community Dent Oral Epidemiol 2004; 32: 54-61.

24. Chestnutt I G, Schäfer F, Jacobson A P, Stephen K W. The influence of toothbrushing frequency and post-brushing rinsing on caries experience in a caries clinical trial. Community Dent Oral Epidemiol. 1998; 26: 406-411.

25. Ashley P F, Attrill D C, Ellwood R P, Worthington $H$ V, Davies R M. Toothbrushing habits and caries experience. Caries Res 1999; 33: 401-402.

26. O'Mullane D M, Kavanagh D, Ellwood R P et al. A three-year clinical trial of a combination of trimetaphosphate and sodium fluoride in silica toothpastes. J Dent Res 1997: 76: 1776-1781.

27. Marinho V C, Higgins J P, Sheiham A, Logan S Combinations of topical fluoride (toothpastes, mouthrinses, gels, varnishes) versus single topical fluoride for preventing dental caries in children and adolescents. Cochrane Database Syst Rev 2004; (1): CD002781.

28. Petersson L G, Hakestam U, Baigi A, Lynch E. Remineralization of primary root caries lesions using an amine fluoride rinse and dentifrice twice a day. Am J Dent 2007; 20: 93-96.

29. Department of Health and British Association for the Study of Community Dentistry. Delivering better oral health - an evidence-based toolkit for prevention. 2nd Ed. BASCD, 2009. Online article available at http://www.dh.gov.uk/ en/Publicationsandstatistics/Publications/ PublicationsPolicyAndGuidance/DH_102331 (accessed June 2011).

30. Australian Research Centre for Population Oral Health. The use of fluorides in Australia: guidelines. Aust Dent J 2006; 51: 195-199.

31. New Zealand Guidelines Group. Guidelines for the use of fluorides. Wellington: New Zealand Ministry for Health, 2009. Online article available at www.nzgg.org.nz (accessed October 2010).

32. Aasenden R, Brudevold F, Richardson B. Clearance of fluoride from the mouth after topical treatment or the use of a fluoride mouthrinse. Arch Oral Biol 1968; 13: 625-636.

33. Bruun C, Lambrou D, Larsen M J, Fejerskov O,
Thylstrup A. Fluoride in mixed human saliva after different topical fluoride treatments and possible relation to caries inhibition. Community Dent Oral Epidemio/ 1982; 10: 124-129.

34. Duckworth R M, Morgan S N, Murray A M. Fluoride in saliva and plaque following use of fluoride-containing mouthrinses. J Dent Res 1987 . 66: $1730-1734$

35. Ekstrand J. Fluoride in plaque fluid and saliva after NaF or MFP rinses. Eur J Oral Sci 1997: 105: 478-484.

36. Vogel G L, Zhang Z, Carey C M, Ly A, Chow LC, Proskin $\mathrm{H}$ M. Composition of plaque and saliva following use of an alpha-tricalcium-phosphatecontaining chewing gum and a subsequent sucrose challenge. J Dent Res 2000; 79: 58-62.

37. Aasenden R, DePaola P F, Brudevold F. Effects of daily rinsing and ingestion of fluoride solutions upon dental caries and enamel fluoride. Arch Oral Biol 1972; 17: 1705-1714.

38. Birkeland, J M, Lökken P. The pharmacokinetics of fluoride in mouth rinses as indicated by reference substance (51Cr-EDTA). Caries Res 1972; 6: 325-333.

39. Driscoll W S, Swango P A, Horowitz A M, Kingman A. Caries-preventive effects of daily and weekly fluoride mouthrinsing in a fluoridated community: final results after 30 months. J Am Dent Assoc 1982; 105: 1010-1013.

40. Heifetz S B, Meyers R J, Kingman A. Comparison of the anticaries effectiveness of daily and weekly rinsing with sodium fluoride solutions: findings after three years. Pediatr Dent 1983; 4: 300-303.

41. Zero D T, Raubertas R F, Fu J, Pederson A M, Hayes $A$ L, Featherstone J D. Fluoride concentrations in plaque, whole saliva and ductal saliva after application of home-use topical fluorides. J Dent Res 1992; 71: 1768-1775.

42. Koch G, Petersson L G, Rydén H. Effect of fluoride varnish (Duraphat) treatment every six months compared with weekly mouthrinses with 0.2 per cent $\mathrm{NaF}$ solution on dental caries. Swed Dent J 1979; 3: 39-44.

43. Blinkhorn A S, Holloway P J, Davies T G. Combined effects of a fluoride dentifrice and mouthrinse on the incidence of dental caries. Community Dent Oral Epidemiol 1983; 11: 7-11.

44. Billings R J, Meyerowitz C, Featherstone J D et al.
Retention of topical fluoride in the mouths of xerostomic subjects. Caries Res 1988; 22: 306-310.

45. Sarner B, Birkhed D, Lingström P. Approximal fluoride concentration using different fluoridated products alone or in combination. Caries Res 2008; 42: 73-78.

46. Scottish Intercollegiate Guidelines Network. Preventing dental caries in children at high caries risk. Targeted prevention of dental caries in the permanent teeth of 6-16-year-olds presenting for dental care. SIGN 47. Edinburgh: SIGN, 2000. Online article available at http://www.sign.ac.uk/ pdf/sign47.pdf (accessed July 2010)

47. Scottish Intercollegiate Guidelines Network. Prevention and management of dental decay in the pre-school child. SIGN 83. Edinburgh: SIGN, 2005. Online article available at http://www.sign.ac.uk/ pdf/sign83.pdf (accessed July 2010).

48. Irish Oral Health Services Guideline Initiative. Strategies to prevent dental caries in children and adolescents: evidence-based guidance on identifying high caries risk children and developing preventive strategies for high caries risk children in Ireland. Ireland: Irish Oral Health Services Guideline Initiative, 2009. Online article available at http://ohsrc.ucc.ie/ $\mathrm{html} /$ guidelines.html (accessed October 2010).

49. European Academy of Paediatric Dentistry. Guidelines on the use of fluoride in children: an EAPD policy document. Eur Arch Paediatr Dent 2009: 10: 129-135.

50. Scottish Dental Clinical Effectiveness Programme. Prevention and management of dental caries in children: dental clinical guidance. Dundee: SDCEP, 2010. Online article available at http://www.sdcep. org.uk/index.aspx?o=2332 (accessed October 2010).

51. American Academy of Pediatric Dentistry. Guideline on fluoride therapy. Pediatr Dent 2009; 32 (Suppl 6): 143-146.

52. Marmot M. Fair society, healthy lives - a strategic review of health inequalities in England post-2010 (the Marmot review). Global Health Equity Group, 2010.

53. Kobayashi S, Kishi H, Yoshihara A et al. Treatment and posttreatment effects of fluoride mouthrinsing after 17 years. J Public Health Dent 1995: 55: 229-233. 